\title{
Influence of the gastrocnemius muscle on the sit-and-reach test assessed by angular kinematic analysis
}

\author{
Influência do músculo gastrocnêmio sobre o teste sentar e alcançar avaliada pela \\ análise cinemática angular
}

Marcio M. Kawano', Gabriel Ambar², Beatriz I. R. Oliveira², Marcela C. Boer², Ana P. R. G. Cardoso², Jefferson R. Cardoso ${ }^{3}$

\begin{abstract}
Background: The sit-and-reach test (SRT) used to measure low back and hamstring flexibility is more adequate when combined with hip joint angle (HJA) measurement. It is supposed that shortening of the gastrocnemius muscle could affect the SRT results. Objectives: The purposes of the study were to investigate the relationship between the HJA and SRT and to verify the influence of the gastrocnemius. Methods: This is a cross-sectional study on healthy subjects. Two hundred subjects took part in the study: 100 males and 100 females aged 21.2 years (SD=1.7). The materials used were a sit-and-reach box with an adapted door to evaluate the influence of the gastrocnemius and a digital camera. Skin markers were positioned on the anterior superior iliac spine and greater trochanter. Two pictures were taken in the final position of the test, one with the door closed (with ankle dorsiflexed - DF) and the other with the door opened (with ankle plantarflexed - PF). Results: Moderate correlation was found between the HJA and SRT for DF and PF ( $r=0.48$ e 0.44). The HJA with DF and PF were $95.5^{\circ} \pm 18.6^{\circ}$ and $99.7^{\circ} \pm 18^{\circ}(P<0.001)$, respectively. Conclusions: Angular kinematic analysis is a reliable technique to measure the HJA. The results demonstrated the influence of the gastrocnemius; thus we suggest that the SRT be performed with free ankle joint mobility.
\end{abstract}

Key words: biomechanics; hip joint; physical examination.

\section{Resumo}

Contextualização: O teste sentar e alcançar (TSA) usado para medir a flexibilidade lombar e dos músculos isquiotibiais é mais adequado quando usado concomitantemente para avaliar o ângulo da articulação do quadril (AAQ). Acredita-se que o encurtamento do músculo gastrocnêmio afetaria os resultados desse teste. Objetivos: As propostas deste estudo foram correlacionar os resultados do ângulo do quadril e do teste sentar e alcançar e verificar a influência do músculo gastrocnêmio. Métodos: Foi realizado um estudo transversal que envolveu sujeitos saudáveis. Duzentos sujeitos participaram do estudo: 100 homens e 100 mulheres, com idade média de 21,2 anos (DP=1,7). Os materiais usados foram um banco do TSA com uma porta adaptada para avaliar a influência do músculo gastrocnêmio e câmera fotográfica digital. Marcadores cutâneos foram posicionados na espinha ilíaca ântero-superior e trocânter maior. Realizaram-se duas aquisições de imagem: uma com porta fechada (tornozelo em dorsiflexão TD) e outra aberta (tornozelo em flexão plantar - TF). Resultados: Correlação moderada foi encontrada entre AAQ e TSA, tanto para TD como para TF ( $r=0,48$ e 0,44). Os ângulos encontrados com a porta fechada e aberta foram, respectivamente, $95,5^{\circ} \pm 18,6^{\circ}$ e $99,7^{\circ} \pm 18^{\circ}(P<0,001)$. Conclusões: A análise cinemática angular é uma técnica confiável de avaliação do AAQ. A influência do músculo gastrocnêmio foi observada; portanto, sugere-se deixar o tornozelo livre durante a realização do TSA.

Palavras-chave: biomecânica; articulação de quadril; exame físico.

Received: 17/03/2008 - Revised: 11/11/2008 - Accepted: 30/06/2009

${ }^{1}$ Physical Therapy Course, Faculdade São Francisco de Barreiras (FASB), Barreiras (BA), Brazi

${ }_{2}$ Physical Therapist

${ }^{3}$ Department of Physical Therapy, Kinesiologic Electromyography and Kinematics Research Laboratory, Health Sciences Center, Universidade Estadual de Londrina (UEL), Londrina (PR), Brazil Correspondence to: Jefferson Rosa Cardoso, Hospital Universitário Regional, Norte do Paraná, Departamento de Fisioterapia, Av. Robert Kock, 60, CEP 86038-440, Londrina (PR), Brazil, e-mail: jeffcar@uel.br 


\section{Introduction $: \therefore$.}

The Sit-and-Reach Test (SRT) described by Wells and Dillon in the 1950s is commonly used to measure low back and hamstring flexibility. The interest in studying the hamstring muscles and the measure of their length is due to possible injuries caused by biomechanical changes that lead to certain dysfunctions: patellofemoral joint dysfunction, pubic pain, low back pain, patellar tendonitis and postural deviations ${ }^{2-7}$. Although this test is widely used in many fitness batteries, it is believed that certain factors could alter the SRT results ${ }^{8.9}$. Some authors suggest the following factors are mainly responsible: disproportion between the upper and lower limbs relative to the trunk ${ }^{10}$; scapular abduction, which increases the reaching distance of the arms ${ }^{11}$; and SRT scores that do not distinguish the contributions of the low back or hamstring muscles during the test. Moreover, the SRT is commonly used to assess low back flexibility; however previous studies presented a low correlation between SRT and low back flexibility. These authors do not recommend the use of the SRT to measure low back flexibility ${ }^{12,13}$.

Different SRTs and their modified versions have been studied with the intention of eliminating these factors. Some examples are: Back Saver Sit-and-Reach Test, Modified Back Saver Sit-and-Reach Test, Chair Sit-and-Reach Test, Modified Sit-and-Reach Test and V-Sit-and-Reach Test ${ }^{8,10,14-17}$. All of these tests considered the final position that the subjects reached, but not the angle of the hip joint. The length of the hamstring muscle can be measured by the inclination angle of the sacrum and pelvis, related to the horizontal line at the point of maximal forward reach on the SRT ${ }^{18}$. This represents an indirect measure of the hip joint angle (HJA). Furthermore, when the HJA is used in the SRT, differences in length of upper and lower limbs and contribution of low back can be eliminated ${ }^{18}$.

The HJA can be assessed by using angular kinematic analysis. It is a method of measuring movement parameters (position and orientation), which can be easily performed with digital photography in order to determine joint configuration. Digital imaging has been quite useful as a method of taking precise kinematic measurements. These images can be used to calculate joint angles using specific software ${ }^{19,20}$.

The gastrocnemius is a two-joint muscle that spans the knee and the ankle joints. In spite of the fact that the gastrocnemius has no relationship with the hip, this muscle can alter the SRT result because it crosses the knee. Thus, when the subject performs a trunk forward flexion in a sitting position, with the knee fully extended and the ankle dorsiflexed, all posterior muscles (hamstrings and gastrocnemius) will be in tension ${ }^{21,22}$. During the standard SRT the subjects put the ankle in dorsiflexion position (DF) with the knee fully extended. When the subject performs trunk forward flexion with the knee extended and ankle in dorsiflexion, an uncomfortable tension can be felt in the gastrocnemius if this muscle is shortened and this is the limiting factor to continue the test. Thus, the subject will be unable to stretch the hamstring maximally because of the previous gastrocnemius tension (discomfort). This can explain the limited HJA movement. We believe that the standard SRT with ankle DF is not the best form of measuring hamstring flexibility. It is supposed that performing the SRT with the ankle plantarflexed (PF) is the best way to evaluate only hamstring muscle flexibility, because the gastrocnemius muscles will be in a relief position and the discomfort in the calf will not occur. This would improve the performance in HJA. Therefore, the objectives of this study were: (1) to measure the HJA as an indirect measure of hamstring flexibility, (2) to investigate whether there is a relationship between HJA and SRT, (3) to verify the influence of the gastrocnemius muscles on SRT and (4) to compare these results between men and women.

\section{Methods : :}

\section{Subjects}

A total of 200 university students took part in the study: 100 males and 100 females; having a mean age of 21.2 years ( $\mathrm{SD}=1.7$ ), a mean height of $169 \mathrm{~cm}(\mathrm{SD}=0.09)$, a mean mass of $63.3 \mathrm{~kg}$ $(\mathrm{SD}=12.4)$ and a mean body mass index of $21.8 \mathrm{~kg} / \mathrm{m}^{2}(\mathrm{SD}=2.7)$. The inclusion criteria were: apparent health, age between 18 and 25 , and physical activity two to four times per week. The initial sample size was 204 subjects; however four subjects dropped out because of the following exclusion criteria: pain, postural deviation, previous back and limb surgery or spine/lower extremity injuries in the six months prior to data collection. All inclusion and exclusion criteria were evaluated by two experienced physical therapists. The intensity of the pain was determined by the visual analogue scale $(10 \mathrm{~cm})$ and injuries were determined by questionnaire. The subjects signed an informed consent form approved by the Human Research Ethics Committee of Universidade Estadual de Londrina, Brazil (CEP 058/04).

\section{Instrumentation}

A wooden box $30.5 \mathrm{~cm}$ x $30.5 \mathrm{~cm} \times 30.5 \mathrm{~cm}$ with a fixed 23 centimeter ruler on top was used in the study. A door was built measuring $27 \mathrm{~cm}$ in height and $27 \mathrm{~cm}$ in width on the side where the subjects placed their feet against the box, permitting assessment of the influence of the gastrocnemius during SRT. When the door was closed, the ankles were in 
a DF position (gastrocnemius was taut), and when the door was opened, the ankles were in a PF position (gastrocnemius was slack). Initially, a digital camera (5.1 megapixels) was square and plumb and directly perpendicular to the axis of the HJA. The camera was level and parallel to the floor and positioned on a tripod at $40 \mathrm{~cm}$ above the floor and $202 \mathrm{~cm}$ from the background, always focused on the hip joint. The camera captured the subject's entire field of vision without the use of the zoom. All of these procedures were carefully prepared to avoid motion parallax errors. Two photographs of each subject were taken, one with the door closed (with ankle DF) and the other when open (with ankle PF; Figures 1A and $1 \mathrm{~B}$, respectively). The order of the test was random. The measurement of the photographs took place in the Laboratory of Kinesiologic Electromyography and Kinematics during the same period of the day for all subjects.

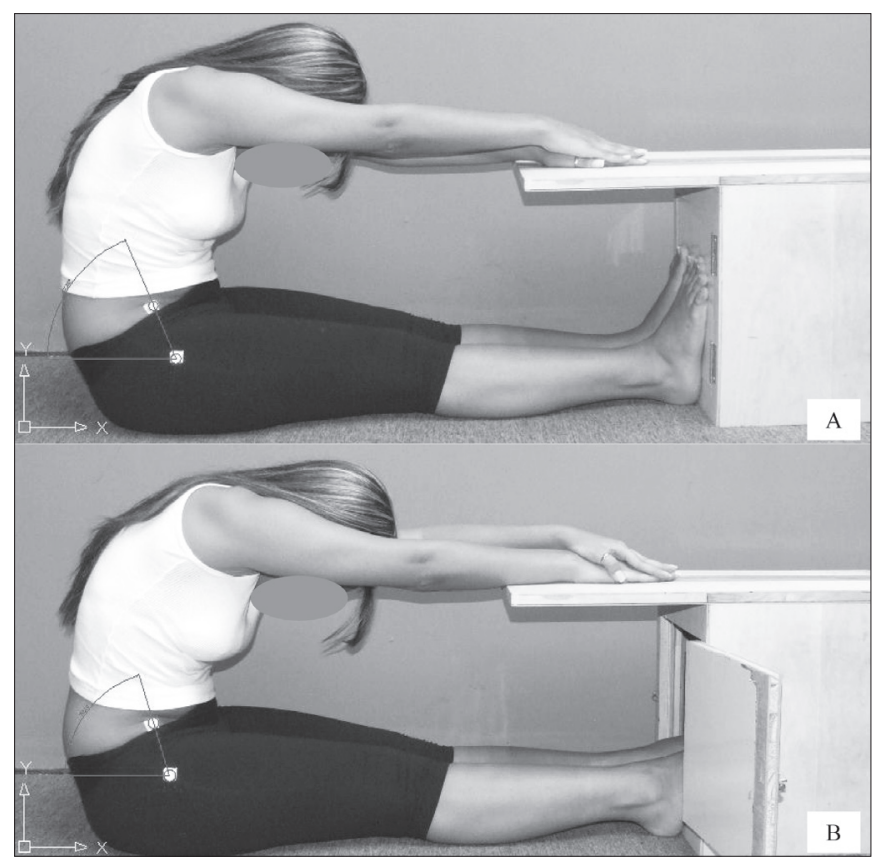

Figure 1. A) Sit-and-reach test with the door closed (with ankle DF); B) with the door opened (with ankle PF). The hip joint angle formed by two lines: one line between the anterior superior iliac spine and greater trochanter references, and the other, a horizontal line along the greater trochanter reference.

Table 1. Anthropometric values of the subjects according to gender.

\begin{tabular}{lcccc}
\hline & \multicolumn{2}{c}{ Men $(\mathrm{n}=100)$} & \multicolumn{2}{c}{ Women $(\mathrm{n}=100)$} \\
& $\overline{\mathrm{x}}(\mathrm{SD})$ & Range & $\overline{\mathrm{x}}(\mathrm{SD})$ & Range \\
\hline Age (years) & $21.6(1.9)$ & $18-25$ & $20.8(1.4)$ & $19-25$ \\
\hline Mass $(\mathrm{kg})$ & $72.1(11)$ & $49-110$ & $55.2(6.8)$ & $41.5-79.7$ \\
\hline Height $(\mathrm{cm})$ & $176.0(7.1)$ & $159-199$ & $163.0(6.3)$ & $148.0-181.0$ \\
\hline BMl $\left(\mathrm{kg} / \mathrm{m}^{2}\right)$ & $23.1(2.6)$ & $17.7-31.8$ & $20.6(2.3)$ & $13.1-28.5$ \\
\hline
\end{tabular}

$\overline{\mathrm{X}}=$ mean; $\mathrm{SD}=$ standard deviation; $\mathrm{BMI}=$ body mass index.

\section{Procedures}

Reflective skin markers of one centimeter in diameter were positioned on the anterior superior iliac spine (ASIS) and greater trochanter (GT) by two experienced physical therapists. The ASIS and the GT are relatively large areas of reference, and they need specific standardized assessment. Later, with the hips flexed, knees straightened and feet fully placed against the box door (DF) or in PF, the subjects extended their arms forward, placing one hand on the top of the other. With palms down, the participant reached forward over the measuring scale as far as possible, without bending the knees, and held the position for approximately two seconds. If the knees were not straightened, the subject had to repeat the test and a new picture was taken. An initial training session was held to provide familiarization with the experimental equipment and procedures the day before.

The subjects performed one reaching movement for each box position. Two pictures were taken in this final body position, one with DF and the other with PF; a total of 400 pictures were taken. The maximum reach according to the ruler on the box was the SRT value, and the HJA was calculated using the software CorelDraw $^{\circledR}$ version 11. The HJA was measured by the inclination angle of the sacrum and pelvis, related to the horizontal line, at the point of maximal forward reach on the SRT as measured in the Cornbleet et al. ${ }^{18}$ study. To obtain this angle two lines were required: one between the ASIS and GT references, and the other, a horizontal line along the GT reference (Figure 1, A and B). The lines were digitally drawn on the pictures, and the software gave the angles between the lines.

\section{Statistical analysis}

The SRT variables were tested considering normal distribution, using the Shapiro-Wilk test. ANOVA with one repeatedmeasures factor was used to compare the results of the HJA with ankle DF and PF and of the HJA results between genders. The analysis was complemented by means of the Tukey multiple comparison test. Both comparisons were followed by their confidence intervals ( $95 \% \mathrm{CI}$ ). To investigate the relationship between the HJA and the SRT, the Pearson product-moment correlation coefficient was applied. Statistical significance was stipulated at 5\% $(P<0.05)$. The Statistical Package for Social Sciences (SPSS) version 13.0 was used for statistical analysis.

\section{Results : :}

The anthropometric values, separated according to gender, are presented in Table 1. The HJA values of the sample, with ankle DF and PF were respectively: $\bar{x}=95.5^{\circ}\left(\mathrm{SD}=18.6^{\circ}\right)$ 
Table 2. HJA and SRT values with ankle dorsiflexed (DF) and plantarflexed (PF) according to gender.

\begin{tabular}{|c|c|c|c|c|c|c|}
\hline & \multicolumn{2}{|c|}{ Men } & \multicolumn{2}{|c|}{ Women } & \multirow[b]{2}{*}{$\mathrm{Cl} 95 \%$} & \multirow[b]{2}{*}{$P$} \\
\hline & $\bar{x}(\mathrm{SD})$ & Range & $\bar{x}(\mathrm{SD})$ & Range & & \\
\hline HJA - with ankle DF $\left(^{\circ}\right)$ & $83.0^{\circ}\left(14.2^{\circ}\right)$ & $49.4^{0}-114.8^{\circ}$ & $107.9^{\circ}\left(13.3^{\circ}\right)$ & $73.5^{0}-144.8^{\circ}$ & {$[21 ; 28.7]$} & $<0.001$ \\
\hline HJA - with ankle PF $\left(^{\circ}\right)$ & $87.3^{\circ}\left(13.4^{\circ}\right)$ & $53.6^{0}-117.5^{\circ}$ & $112.1^{0}\left(12.6^{\circ}\right)$ & $82.6^{0}-145.4^{\circ}$ & {$[21.1 ; 28.4]$} & $<0.001$ \\
\hline SRT - with ankle DF (cm) & $27.7(9.1)$ & $6.0-49.5$ & $30.4(7.9)$ & $12.0-49.0$ & {$[0.3 ; 5]$} & 0.027 \\
\hline SRT - with ankle PF (cm) & $32.1(8.4)$ & $10.0-50.5$ & $34.7(6.5)$ & $19.0-51.0$ & {$[0.4 ; 4.6]$} & 0.018 \\
\hline
\end{tabular}

$\mathrm{HJA}=$ hip joint angle; $\mathrm{SRT}=$ sit-and-reach test; $\overline{\mathrm{X}}=$ mean; $\mathrm{SD}=$ standard deviation; Range=minimum and maximum value. $95 \% \mathrm{Cl}=95 \%$ confidence interval.

and $\bar{x}=99.7^{\circ}\left(\mathrm{SD}=18.0^{\circ}\right), 95 \% \mathrm{CI}$ of mean difference $(3.7-4.7$; $P<0.001)$. The SRT results were: $\bar{x}=29.0 \mathrm{~cm}(\mathrm{SD}=8.6 \mathrm{~cm})-\mathrm{DF}$ and $\bar{x}=33.4 \mathrm{~cm}(\mathrm{SD}=7.6 \mathrm{~cm})-\mathrm{PF}, 95 \% \mathrm{CI}$ of mean difference $(3.9-4.8 ; P<0.001)$.

A moderate correlation was obtained between the HJA and SRT values with DF and PF ( $r=0.48$ and $r=0.44$, respectively). When separated according to gender, a moderate correlation between men was found with DF and PF ( $r=0.61$ and $r=0.54$, respectively), whereas between women, a low correlation was found ( $r=0.31$ and $r=0.24$, respectively). The values obtained from analysis of the HJA and SRT by gender are presented in Table 2.

The HJA values for men presented significant statistical differences when comparing DF $\left(\bar{x}=83.0^{\circ}\right)$ with $\mathrm{PF}\left(87.3^{\circ}\right), 95 \% \mathrm{CI}$ of mean difference (3.6 - 4.9; $P<0.0001)$; these were similar to those found for women (DF $\bar{x}=107.9^{\circ}$; PF $\bar{x}=112.9^{\circ}$ ), 95\% CI of mean difference (3.5 - 4.9; $P<0.0001)$.

\section{Discussion $: \because$.}

The present study reveals that there are differences when the SRT and HJA results are compared in two situations: ankle DF or ankle PF. The values of the SRT and HJA with ankle PF were higher than ankle DF. Regarding the HJA values obtained with DF and PF for the entire sample, a significant statistical difference was found. The same occurred when separated according to gender. This demonstrates the influence of the gastrocnemius when the SRT is performed with the door closed or open. The SRT is used to measure hamstring muscle flexibility and not gastrocnemius flexibility. Subjects with shortened gastrocnemius muscle who perform the standard SRT (with a $90^{\circ}$ of ankle $\mathrm{DF}$ ) can lead the physical therapist to attribute the subject's low score to shortened hamstring muscles. This happens because, when the gastrocnemius is shortened, the subject feels discomfort in the gastrocnemius muscle before the hamstring muscle. A tension is created in the calf, and it is a limiting factor to continuing the SRT. This prevents the subject from stretching the hamstring maximally due to great discomfort in the gastrocnemius; at this point, the extremities of the subject's gastrocnemius muscle are apart. As a consequence, the subject will fail to reach the maximal hamstring muscle stretch point. Therefore, by keeping the knee extended and maintaining the ankle in PF position, the gastrocnemius muscles will remain loose and will not interfere with the length of the hamstring muscles during the SRT. Thus, the hamstrings can be stretched maximally. Muscles that perform movements on two joints must be loose on one joint (ankle) to obtain a better range of motion over the other joint (knee) ${ }^{21}$.

A significant statistical difference occurred between the HJA values for men and women. Women presented better hamstring flexibility than men with DF and PF. This finding corroborates previous studies ${ }^{18,23,24}$. In a study with 410 volunteers aged five to 12 years, a mean angle of $81^{\circ}$ was found when measured by an inclinometer ${ }^{18}$. When separated according to gender, the mean angle was $75^{\circ}$ for boys and $85^{\circ}$ for girls, in spite of the fact that they had the same physical activity level (between two and four times per week). This study suggests that, when studying hamstring muscles, differences between genders must be considered.

The correlation between the HJA and SRT with ankle DF and $\mathrm{PF}$ indicated a moderate correlation. These results did not corroborate another study ${ }^{18}$, in which the correlation between the SRT and HJA was measured by using an inclinometer and where a strong correlation $(r=0.76)$ between the angle values and the maximum distance reached was observed. The moderate-to-low correlation presented in the present study was due to the fact that the standard SRT does not consider the differences between limbs, a phenomenon well documented in the literature. The variation in length between the upper and lower limbs in relation to trunk and spine affects measurements of mobility and will interfere in the SRT results. To put it more clearly, a person who has relatively longer arms will achieve a better reaching score, which cannot be attributed to the flexibility of the gastrocnemius but to the arm span. In contrast, angular kinematic analysis, which in this case provides the HJA score, eliminates the proportional differences between upper and lower limbs.

The effect of the head position on the SRT was examined by another study ${ }^{25}$. It considered that the erector spinae muscles were stressed when subjects performed the SRT with the head down, decreasing the possibility of improved trunk flexion when maximum reach was performed. Therefore, the performance of the SRT with the head up decreases stress on these 
muscles, providing better results. The study indicated differences between head positions, but they presented no clinical importance.

The intrarater reliability test (ankle DF and PF) for the HJA analysis presented high reliability after a five-day interval. The reliability of the test was between $96 \%$ and $98 \%$. The same occurred in the interrater reliability test, performed by two trained evaluators, which agreed with a previously published study $^{26}$. The values of the ICC test were between 0.96 and 0.98 . The values of the mean difference of the Bland-Altman test were between 0.01 and 0.07 . These results showed that the technique presents good applicability and that the values of the angle formed by the hip joint are easily calculated.

In all of the SRT studies analyzed, previous hamstring stretching was performed. However, in the present study, the same procedure was not adopted, due to the fact that the viscoelastic properties of muscles have short duration ${ }^{27,28}$. According to Depino et al. ${ }^{27}$, nine minutes after four 30 -second hamstring static stretches, the hamstring length returns to baseline values. This happens because the viscoelastic component was not deformed enough to produce a permanent change $^{27}$. Thus, if hamstring muscles are stretched prior to the performance of the SRT, their true length may not be analyzed. Therefore, if the tests had been repeated twice or more, the SRT values would have been higher than in the first evaluation.

The SRT with the HJA measured by angular kinematic analysis can be performed anywhere a small evaluation lab can be set up. A standard box and a camera are needed to take the photographs. This technique allows a reliable and simple measurement of hamstring length when the evaluator uses the final SRT position (maximum anterior trunk flexion) with neutral ankle position and registers the HJA.

\section{Conclusions : :}

The results of this study demonstrated that the HJA measurement serves as an indirect measurement of hamstring flexibility and could be employed in clinical practice as an outcome measure. It was also demonstrated that the HJA is a more accurate measure of flexibility than the SRT due to the fact that it is uninfluenced by limb length when applied in conjunction with a free ankle joint. Finally, the results of female subjects presented higher values than did those of the males.

\section{References : $:$.}

1. Wells KF, Dillon EK. The sit and reach. A test of back and leg flexibility. Res Q Exerc Sport. 1952;23:115-8.

2. Delee JC, Drez D, Miller MD. Orthopaedic sports medicine: principles and practice. Philadelphia: Saunders; 2003.

3. Witvrouw E, Danneels L, Asselman P, D'Have T, Cambier D. Muscle flexibility as a risk factor for developing muscle injuries in male professional soccer players. A prospective study. Am J Sports Med. 2003;31(1):41-6.

4. Witvrouw E, Bellemans J, Lysens R, Danneels L, Cambier D. Intrinsic risk factors for the development of patellar tendinitis in an athletic population. A two-year prospective study. Am J Sports Med. 2001;29(2):190-5.

5. Hartig DE, Henderson JM. Increasing hamstring flexibility decreases lower extremity overuse injuries in military basic trainees. Am J Sports Med. 1999;27(2):173-6.

6. Woods C, Hawkins RD, Maltby S, Hulse M, Thomas A, Hodson A. The football association medical research programme: an audit of injuries in professional football-analysis of hamstring injuries. Br J Sports Med. 2004;38:36-41.

7. Busquet L. Les chaînes musculaires T.3; La pubalgie. Paris: Frison-Roche; 2001.

8. Baltaci G, Un N, Tunay V, Besler A, Gerçeker S. Comparison of three different sit and reach tests for measurement of hamstring flexibility in female university students. Br J Sports Med. 2003;37(1):59-61.
9. Miñarro PA, Andújar PS, García PL, Toro EO. A comparison of the spine posture among several sit-and-reach test protocols. J Sci Med Sport. 2007;10(6):456-62.

10. Hoeger WW, Hopkins DR. A comparison of the sit and reach and the modified sit and reach in the measurement of flexibility in women. Res $Q$ Exerc Sport. 1992;63(2):191-5.

11. Holt LE, Pelham TW, Burke DG. Modifications to the standard sit and reach flexibility protocol. J Athl Train. 1999;34(1):43-7

12. Jackson AW, Baker AA. The relationship of the sit and reach test to criterion measures of hamstring and back flexibility in young females. Res $Q$ Exerc Sport. 1986;57:183-6.

13. Patterson P, Wilksten DL, Ray L, Flanders C, Sanphy D. The validity and reliability of the back saver sit-and-reach test in middle school girls and boys. Res Q Exerc Sport. 1996;67(4):448-51.

14. Lemmink KA, Kemper HC, de Greef MH, Rispens P, Stevens M. The validity of the sit-and-reach test and the modified sit-and-reach test in middle-aged to older men and women. Res Q Exerc Sport. 2003;74(3):331-7.

15. Minkler S, Patterson P. The validity of the modified sit-and-reach test in college-age students. Res Q Exerc Sport. 1994;65(2):189-92.

16. Jones CJ, Rikli RE, Max J, Noffal G. The reliability and validity of a chair sit-and-reach test as a measure of hamstring flexibility in older adults. Res Q Exerc Sport. 1998;69(4):338-43. 
17. Hui SC, Yuen PY, Morrow JR Jr, Jackson AW. Comparison of the criterion-related validity of sit-and-reach tests with and without limb length adjustment in Asian adults. Res Q Exerc Sport. 1999;70(4):401-8.

18. Cornbleet S, Woolsey N. Assessment of hamstring muscle length in school-aged children using the sit-and-reach test and the inclinometer measure of hip joint angle. Phys Ther. 1996;76(8):850-5.

19. Chen YL. Accuracy and repeatability of the stick marker technique for external measurement of the sacral angle during trunk flexion. Int J Ind Ergon. 2000;26(1):101-7.

20. Liu $Y$, Zhang $X$, Chaffin D. Perception and visualization of human posture information for computer-aided ergonomic analysis. Ergonomics. 1997;40(8):818-33.

21. Kendall FP, McCreary EK, Provance PG. Muscles: testing and function. Baltimore: Lippincott Williams \& Wilkins; 1993.

22. Kapandji Al. Physiologie articulaire T. 2: membre inférieur. Paris: Maloine; 2000.
23. Hui SS, Yuen PY. Validity of the modified back-saver sit-and-reach test: a comparison with other protocols. Med Sci Sports Exerc. 2000;32(9):1655-9.

24. Jackson A, Langford NJ. The criterion-related validity of the sit-and-reach test: replication and extension of previous findings. Res Q Exerc Sport. 1989;60(4):384-7.

25. Smith JF, Miller CV. The effect of head position on sit-and-reach performance. Res Q Exerc Sport. 1985;56:84-5.

26. Cardoso JR, Azevedo NCT, Cassano CS, Kawano MM, AmbarG. Confiabilidade intra e interobservador da análise cinemática angular do quadril durante 0 teste sentar e alcançar para mensurar o comprimento dos isquiotibiais em estudantes universitários. Rev Bras Fisioter. 2007;11(2):133-8.

27. Depino GM, Webright WG, Arnold BL. Duration of maintained hamstring flexibility after cessation of an acute static stretching protocol. J Athl Train. 2000;35(1):56-9.

28. Spernoga SG, Uhl TL, Arnold BL, Gasneder BM. Duration of maintained hamstring flexibility after a one-time, modified hold-relax stretching protocol. J Athl Train. 2001;36(1):44-8. 